\title{
Diarrhea and Colonic Ulcers of Unusual Etiology
}

Yoav Keynan ${ }^{1 *}$, Michael J. Cantor ${ }^{1}$, David Grynspan², Belinda Lategan² and Pamela H. Orr ${ }^{1}$

${ }^{1}$ Department of Internal Medicine, University of Manitoba, Canada

${ }^{2}$ Departement of Pathology, University of Manitoba, Canada

\begin{abstract}
The present report describes a case of chronic diarrhea with several ulcers in the ascending colon in a 47-yearold woman who immigrated to Canada from the Phillipines. A biopsy from affected colon revealed caseating granulomas and culture grew mycobacterium avium subspecies. Polymerase chain reaction from the colonic biopsy specimen confirmed the presence of mycobacterium avium subspecies that was subsequently identified by hsp65 sequence to be mycobacterium avium hominissuis (MAH). Anti-mycobacterial therapy was started but discontinued by the patient. After 6 months a repeat colonoscopy was macroscopically normal and no granulomas could be seen on biopsies taken from normal appearing colonic tissue. The epidemiological features, host-range and laboratory identification of this unusual organism are discussed.
\end{abstract}

Keywords: Mycobacterium avium; Mycobacterium avium hominissuis; Granulomatous colitis

\section{Introduction}

Mycobacterium avium complex includes four subspecies: $M$. avium subsp. avium, M. avium subsp. silvaticum, M. avium subsp. Paratuberculosis (MAP), and M. avium subsp. Hominissuis (MAH) $[1,2]$. They differ in phenotype, nutrient requirements, host range and the ability to cause infection in immunocompromised hosts. The first two, cause a tuberculosis-like illness in birds, while M. avium subsp. Paratuberculosis is associated with Johne's disease, a chronic, granulomatous enteritis, in ruminants and has been suspected to play a role in the pathogenesis of Crohn's disease in humans [3].

MAH has been repeatedly isolated from swine gastrointestinal samples. This Mycobacterium has been isolated from the lymph nodes of tuberculin positive swine in Croatia. Isolates were typed by conventional methods, PCR and hybridization. Most of the isolates belonged to the Mycobacterium avium complex (95.7\%), of these strains M. a. hominissuis accounted for $78.9 \%$ and M. a. avium for the rest of isolates [4]. M. avium subsp. hominissuis has been reported to constitute the predominant cause of MAC-associated lymphadenitis in several species. Several groups have expended the spectrum of mammals where $M$. avium subsp. hominissuis was associated with digestive tract pathology including mesenteric lymphadenitis; farm animals including pigs and cattle in Uganda, dogs in Germany with mesenteric lymphadenitis and in a pet parrot with gastrointestinal lesions [5-10]. These observations suggest an oral route of infection and the ingestion of contaminated water, food, or fomites. More recently a study from France retrospectively examined MAC isolates from lymphadenitis and non-lymphadenitis in humans and identified 67 organisms. MAH was the most common isolated mycobacterium accounting for 53 of the 67. It accounted for 24 of the 25 isolates from cases of lymphadenitis. Patients were generally young, 3 were HIV infected and one suffered from chronic lymphoid leukemia [11]. Although the organism is thought to be acquired through the gastrointestinal tract, isolation from stools is not necessarily associated with disease causation.

\section{Case Report}

A 47 years old woman presented to the gastroenterology clinic for evaluation of mild long-standing intermittent diarrhea. She had diarrhea for several years, reporting 1-2 loose stools daily, without bleeding. No weight loss, abdominal pain or nocturnal symptoms were reported and the symptom severity had not changed during the past two years. She did not have fever, night sweats or cough and no risk factors for acquired immunodeficiency. The patient immigrated from the Philippines 17 years earlier. No personal or family history of tuberculosis could be elicited. Past medical history was significant for essential hypertension controlled with hydrochlorothiazide. The physical examination disclosed a temperature of $36.5^{\circ} \mathrm{C}$, a respiratory rate of 14 breaths $/ \mathrm{min}$, a pulse of 80 beats $/ \mathrm{min}$. The patient had no lymphadenopathy, clubbing, or cyanosis and chest examination was unremarkable. On abdominal examination, bowel sounds were heard and the abdomen was soft and non-tender, liver and spleen were not enlarged.

Tuberculin skin testing was reactive with an induration measuring $20 \mathrm{~mm}$. Esophagogastroduodenoscopy was normal and a colonoscopy revealed 4-5 small ulcers with active oozing of blood in the ascending colon. Biopsies were taken from the ulcers as well as normal appearing segments of the colon. The terminal ileum was visualized and appeared normal.

On pathological examination the terminal ileum was histologically unremarkable. Biopsies of the endoscopically described ulcer of the ascending colon showed ulcer slough and granulation tissue which had acute and chronic inflammatory infiltrates as well as focal giant cell rich granulomas (Figure 1). Colonic epithelium immediately adjacent to the ulcer showed submucosal granulomas laden with conspicuous large multinucleate giant cells and focal central necrosis (Figure 2). The glandular epithelium showed mild architectural distortion and increased lymphoplasmacytic infiltrates but no significant acute inflammation (cryptitis or crypt abscesses). Biopsies of the grossly described ascending colon polyps also showed fragments of heavily inflamed granulation tissue with giant cell rich granulomas and focal

*Corresponding author: Yoav Keynan, Department of Internal Medicine University of Manitoba, Canada, E-mail: keynany@yahoo.com

Received April 02, 2012; Accepted April 17, 2012; Published April 25, 2012

Citation: Keynan Y, Cantor MJ, Grynspan D, Lategan B, Orr PH (2012) Diarrhea and Colonic Ulcers of Unusual Etiology. Mycobac Dis 2:112. doi:10.4172/21611068.1000112

Copyright: @ 2012 Keynan Y, et al. This is an open-access article distributed under the terms of the Creative Commons Attribution License, which permits unrestricted use, distribution, and reproduction in any medium, provided the original author and source are credited. 
Citation: Keynan Y, Cantor MJ, Grynspan D, Lategan B, Orr PH (2012) Diarrhea and Colonic Ulcers of Unusual Etiology. Mycobac Dis 2:112. doi:10.4172/2161-1068.1000112

Page 2 of 2

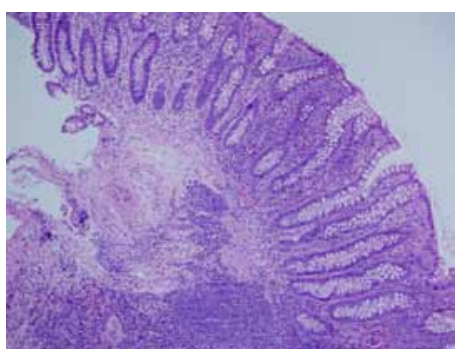

Figure 1: Mildly inflamed surface epithelium with underlying submucosal giant cell rich granulomas. Note the conspicuous, large giant cells.

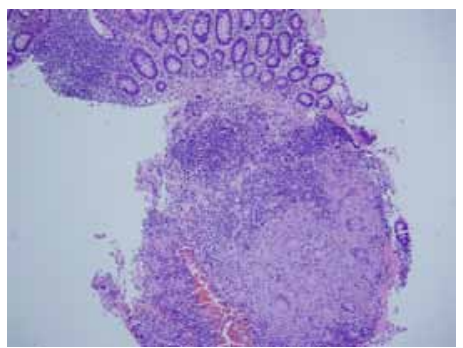

Figure 2: Necrotizing granuloma. The central amorphous eosinophilic material is necrotic debris; there is a peripheral rim of palisading epithelioid histiocytes. Special stains for fungi and acid fast bacilli were negative.

early necrosis. Additional biopsies of the transverse, descending, sigmoid colon and rectum showed only focal lymphoid hyperplasia; the epithelium was unremarkable. Ziehl-Neelsen stain for acid fast bacilli and grocott methenamine silver as well as Periodic-Acid-Schiff (PAS) stain for fungal organisms were negative.

\section{Discussion}

This report describes colonic ulcerative lesions attributed to M. hominissuis. The clinical course, resolution of symptoms and disappearance of colonic ulcers without anti-mycobacterial therapy suggest that this organism may cause a transient infection. Although a causative role could not be stated conclusively, and the disappearance of lesions in the absence of therapy may suggest that the isolated organism was merely a colonizer, the evidence for $\mathrm{MAH}$ as causative agent of lymphadenitis and sometimes disseminated granulomatous inflammation in animals is supportive of virulence of the organism [1113]. Moreover, MAH is capable of causing serious systemic infection in immunocompromised patients, including individuals infected with HIV [14]. Additionally, this pathogen can cause cervical lymphadenitis in immunocompetent host and lung infections in patients with underlying lung disease $[11,15]$.

Mycobacterium avium complex includes four subspecies, in humans. M. avium subsp. Paratuberculosis has a speculated, but unproven role in the pathogenesis of inflammatory bowel diseases. The lesion seen in the patient reported herein, was similar to those observed in Crohn's disease. Agdestein et al. [16] inoculated pigs with M. avium subsp. Avium and $\mathrm{MAH}$ and compared clinical manifestations, shedding of the organism and pathology. The study indicated slightly more pathology with MAH along with significantly longer shedding.
The availability of PCR for speciation of organisms within the $M$. avium complex has led to improved understanding of the animal reservoirs, duration and sites of colonization and relationship to disease processes in animals. This case highlights a possible role for MAH in transient colonic ulceration. Further studies are needed to establish the possible role of this mycobacterial species in human colonic disease.

\section{References}

1. Thorel MF, Krichevsky M, Lévy-Frébault VV (1990) Numerical taxonomy of mycobactin-dependent mycobacteria, emended description of Mycobacterium avium, and description of Mycobacterium avium subsp. avium subsp. nov., Mycobacterium avium subsp. paratuberculosis subsp. nov., and Mycobacterium avium subsp. silvaticum subsp. nov. Int J Syst Bacteriol 40: 254-260.

2. Turenne CY, Collins DM, Alexander DC, Behr MA (2008) Mycobacterium avium subsp. paratuberculosis and $M$. avium subsp. avium are independently evolved pathogenic clones of a much broader group of $M$. avium organisms. J Bacteriol 190: 2479-2487.

3. Feller M, Huwiler K, Stephan R, Altpeter E, Shang A, et al. (2007) Mycobacterium avium subspecies paratuberculosis and Crohn's disease: a systematic review and meta-analysis. Lancet Infect Dis 7: 607-613.

4. Cvetnić Z, Spicić S, Benic M, Katalinić-Janković V, Pate M, et al. (2007) Mycobacterial infection of pigs in Croatia. Acta Vet Hung 55: 1-9.

5. Glawischnig W, Steineck T, Spergser J (2006) Infections caused by Mycobacterium avium subspecies avium, hominissuis, and paratuberculosis in free-ranging red deer (Cervus elaphus hippelaphus) in Austria, 2001-2004. J Wildl Dis 42: 724-731.

6. Möbius P, Lentzsch P, Moser I, Naumann L, Martin G, et al. (2006) Comparative macrorestriction and RFLP analysis of Mycobacterium avium subsp. avium and Mycobacterium avium subsp. hominissuis isolates from man, pig, and cattle. Vet Microbiol 117: 284-291.

7. Domingos M, Amado A, Botelho A (2009) IS1245 RFLP analysis of strains of Mycobacterium avium subspecies hominissuis isolated from pigs with tuberculosis lymphadenitis in Portugal. Vet Rec 164: 116-120.

8. Oloya J, Kazwala R, Lund A, Opuda-Asibo J, Demelash B, et al. (2007) Characterisation of mycobacteria isolated from slaughter cattle in pastora regions of Uganda. BMC Microbiol 7: 95.

9. Haist V, Seehusen F, Moser I, Hotzel H, Deschl U, et al. (2008) Mycobacterium avium subsp. Hominissuis infection in 2 pet dogs, Germany. Emerg Infect Dis 14: $988-990$.

10. Shitaye EJ, Grymova V, Grym M, Halouzka R, Horvathova A, et al. (2009) Mycobacterium avium subsp. hominissuis infection in a pet parrot. Emerg Infect Dis 15: 617-619.

11. Despierres L, Cohen-Bacrie S, Richet H, Drancourt M (2011) Diversity of Mycobacterium avium subsp. hominissuis mycobacteria causing lymphadenitis, France. Eur J Clin Microbiol Infect Dis.

12. Bruijnesteijn van Coppenraet LE, de Haas PE, Lindeboom JA, Kuijper EJ, van Soolingen D (2008) Lymphadenitis in children is caused by Mycobacterium avium hominissuis and not related to 'bird tuberculosis'. Eur J Clin Microbio Infect Dis 27: 293-299.

13. Pavlik I, Svastova P, Bartl J, Dvorska L, Rychlik I (2000) Relationship between IS901 in the Mycobacterium avium complex strains isolated from birds animals, humans, and the environment and virulence for poultry. Clin Diagn Lab Immunol 7: 212-217.

14. Biet F, Boschiroli ML, Thorel MF, Guilloteau LA (2005) Zoonotic aspects of Mycobacterium bovis and Mycobacterium avium-intracellulare complex (MAC). Vet Res 36: 411-436.

15. Inderlied CB, Kemper CA, Bermudez LE (1993) The Mycobacterium Avium complex. Clin Microbiol Rev 6: 266-310.

16. Agdestein A, Johansen TB, Kolbjørnsen O, Jørgensen A, Djønne B, et al. (2012) A comparative study of Mycobacterium avium subsp. avium and Mycobacterium avium subsp. hominissuis in experimentally infected pigs. BMC Vet Res 8: 11 